\title{
School Personnel and Leadership Collaboration Model for Ideal Work Contexts
}

\author{
Brandis M. Ansley \\ Central Michigan University \\ Melanie Blinder \\ Georgia State University \\ Josephine Demere \\ Georgia State University \\ Kris Varjas \\ Georgia State University \\ Gwendolyn Benson \\ Georgia State University \\ Susan L. Ogletree \\ Georgia State University
}

This article describes the school personnel and leadership collaboration (SPLC) model, a shared-responsibility framework for faculty, staff, and administrators. Prior research consistently demonstrates the need for (a) administrative support for teachers and other school personnel and (b) collegial support among staff. The SPLC model represents an amalgamation of this research and, moreover, integrates personnel support for leadership. In the managerial sciences, leader-member exchange (LMX) is a well-known relationship-based leadership approach that focuses on a dyadic or two-way relationship between supervisors and their employees. Though managers are responsible for overseeing operations, personnel contribute ideas, participate in decision-making, and follow through with their responsibilities. LMX is associated with positive work experiences and job performance outcomes. In contrast, schools are often run with a top-down leadership approach that solicits little to no input from staff, leading to low morale, high attrition rates, and negative school climate. Thus, the SPLC model was inspired by LMX and emphasizes practices, such as shared decision-making, staff autonomy, and shared responsibilities. Detailed examples of ways schools may apply the SPLC model to their practices are included.

Keywords: administration, effective leadership, work context, shared responsibility

The authors disclosed receipt of the following financial support for the research and/or authorship of this article. Funding for this research was provided by the U.S. Department of Education through the following grants awarded to Georgia State University: Collaboration and Resources for Encouraging and Supporting Transformations in Education (Award Number U336S140036) and Project Leaders in Exceptionalities Alternative and DelinquencyRelated Environments Through Research and Scholarship (Award Number H325D110030). The contents of this report do not necessarily represent the policy of the Department of Education or endorsement by the federal government. 


\section{Introduction}

Research (e.g., Ansley, Houchins, \& Varjas, 2019; Bettini, Cheyney, Wang, \& Leko, 2015; Robinson, Bridges, Rollins, \& Schumaker, 2019; Simon \& Johnson, 2015; Stewart-Banks, Kuofie, Hakim, \& Branch, 2015) consistently suggests administrative support is a strong predictor of positive working conditions, higher job satisfaction, and lower turnover for teachers and other school personnel. With administrative support, school staff are more empowered to perform their jobs effectively (Bettini, Crockett, Brownell, \& Merrill, 2016; Simon \& Johnson, 2015; Stewart-Banks et al., 2015). Desired school leadership characteristics include (a) consistent enforcement of school procedures (Kraft et al., 2015; Simon \& Johnson, 2015), (b) systematic induction and mentoring programs for new personnel (Bettini et al., 2016; Billingsley, 2010; Borman \& Dowling, 2008; Vittek, 2015), (c) frequent and constructive communication (Bettini et al., 2016; Kraft et al., 2015; Simon \& Johnson, 2015), and (d) equitable workloads and planning time (Bettini et al., 2016; Billingsley, 2010; Simon \& Johnson, 2015). Though much research (e.g., Ansley et al., 2019; Bettini et al., 2016) has demonstrated the importance of administrative support for teachers and other school personnel, there are no known studies that have suggested ways that personnel may support their leadership. Therefore, the purpose of this article is to describe the school personnel and leadership collaboration (SPLC) model. The model is based on previous research regarding school leadership and working conditions (e.g., Ansley et al., 2019; Bettini et al., 2016) and details how school personnel and administrators collaboratively create ideal work contexts that also foster ideal learning environments that promote student growth and development.

The process of operating a school and educating the students has often been viewed as a top-down approach with a clear power differential (Borman \& Dowling, 2008). Teachers and other staff members are responsible for students, while administrators are responsible for personnel and students. In school operations, administrators issue directives to faculty and staff. However, leadership styles that have included shared decision making with school personnel, autonomy and flexibility in their roles, and frequent communication and feedback have been associated with higher quality job performance and desirable student learning outcomes (Bettini et al., 2015; Simon \& Johnson, 2015; Stewart-Banks et al., 2015). The SPLC model promotes mutual respect and teamwork between school personnel and leadership and therefore cultivates healthy professional relationships that empower strong school communities.

\section{Best Leadership Practices}

The managerial sciences literature has often described favorable outcomes associated with organizations that apply leader-member exchange (LMX) to their operations (Dulebohn, Bommer, Liden, Brouer, \& Ferris, 2012). LMX is a relationship-based approach to leadership that focuses on the dyadic or two-way relationship between supervisors and their employees (Graen \& Uhl-Bien, 1995). Working relationships based on trust and respect promote collaboration between leadership and personnel versus a top-down approach (Bauer \& Ergoden, 2015). Managers maintain responsibility for issuing directives and enforcing them. Personnel then collaborate with their supervisors (e.g., contribute ideas, participate in decision-making, follow through with responsibilities) while complying with leader-issued directives (Graen \& Uhl-Bien, 1995). LMX assumes competence and cooperation from all workers and has been associated with positive work experiences and job performance outcomes (Dulebohn et al., 2012; Ilies, Nahrgang, \& Morgeson, 2007). 
In schools, LMX translates to personnel and administrators working cooperatively to deliver best practices to students. As such, the authors developed the SPLC model through research that suggests (a) LMX is an effective organizational management practice (Dulebohn et al., 2012; Ilies et al., 2007), (b) school leadership sets the tone for personnel work contexts (Bettini et al., 2016; Kraft et al., 2015; Simon \& Johnson, 2015; Stewart-Banks et al., 2015), and (c) active participation of faculty and staff is essential to school operations (Bettini et al., 2015; Billingsley, 2010). The SPLC model reflects a collaborative dynamic between school administrators and their faculty and staff and is illustrated in Figure 1.

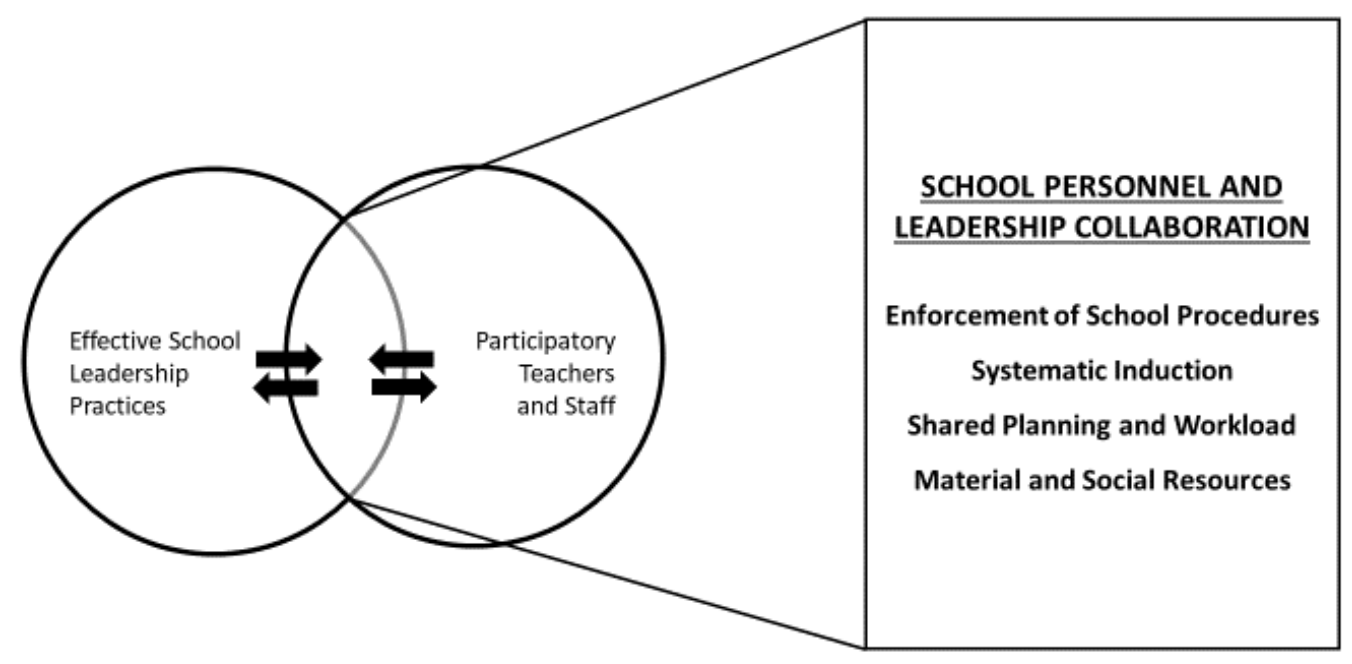

Figure 1. The School Personnel and Leadership Collaboration Model, Illustrating the Necessary Dynamics Between School Administrators and Personnel for Supporting Effective Leadership Practices That Cultivate Ideal Work Contexts and Healthy Learning Environments

\section{Application Examples of the Model}

The SPLC model consists of components that, according to research, are critical for nurturing positive school work contexts (e.g., Ansley et al., 2016; Stewart-Banks et al., 2015). Implementation of this model goes beyond administrative directives and personnel compliance. Rather, these dynamics value personnel input in tandem with administrative decisions. Highly engaged faculty and staff collaborate with school leaders by communicating ideas, contributing to teamwork, and making positive working relationships a priority. The following sections describe how the SPLC model might work in a school. Applications of the SPLC model are centered on four areas commonly addressed throughout literature reviews on school work context studies (e.g., Bettini et al., 2016; Simon \& Johnson, 2015). The authors have delineated personnel and leadership collaboration according to the following major dimensions: (a) enforcement of school procedures, (b) systematic induction and mentoring, (c) shared planning and workload, and (d) material and social resources. 


\section{Enforcement of School Procedures}

Personnel report greater job satisfaction, less occupational stress, and healthy working relationships when school leaders consistently enforce school procedures (Simon \& Johnson, 2015; Stewart-Banks et al., 2015). A prime example involves student behaviors. Using the SPLC model, administrators support faculty enforcement of student behaviors (e.g., deciding not to reinforce inappropriate behavior, withholding incentives, contacting a parent), rather than overriding them (e.g., insisting student receives unearned incentive, placing a teacher in a defensive position with the parent). Yet, if the staff member requests additional assistance with student behaviors, the administrator will provide it (e.g., conferencing with parent or student, administrative actions). Likewise, personnel also must follow the established protocol for student behavior management. Staff and school leadership support each other when they consistently enforce schoolwide behavior codes. Upholding student behavior expectations, such as those related to dress code, bullying, and electronic devices, is not optional. Similarly, apart from severe disruptions affecting others' safety (e.g., fighting, threats of violence), faculty and staff support their administrators by attempting to resolve behavior issues before seeking administrative support. This may include parental contact, withholding reinforcement, differential reinforcement, or any other strategies to redirect students. Otherwise, teachers and staff not only overload administrators with student discipline issues they could have addressed on their own, but they also disempower their authority to set boundaries and manage student behaviors within their learning environments.

Consistent enforcement also refers to management of personnel issues, such as faculty and staff expectations. Employee morale, efficacy, and job satisfaction are all associated with fair and consistent leadership practices (Borman \& Dowling, 2008; Simon \& Johnson, 2015; Stewart-Banks et al., 2015). For example, school personnel are typically expected to abide by certain rules pertaining to attendance, tardiness, or professional attire. When such standards are enforced inconsistently (e.g., strict with some personnel but not with others, rigidly enforced at times after a period of laissez-faire leadership), staff may resent their supervisors rather than support them. In a culture of predictability, fairness, and mutual respect, however, staff members are more cohesive, perform more effectively, and cultivate supportive learning environments (Borman \& Dowling, 2008; Simon \& Johnson, 2015; Stewart-Banks et al., 2015). The following is an example of how the SPLC model can be applied to enforcement of student behaviors as well as faculty and staff expectations:

Preplanning began with a typical new school year meeting. Freedom High School, a highneed school (e.g., large percentage of students experiencing poverty, low student achievement indicators) has a long-established pattern of low morale and high turnover among faculty and staff. Wanda, the enthusiastic new principal, was excited to begin this phase of her career. She was assigned to lead three assistant principals, 54 certified teachers, and 12 other personnel (e.g., counselors, social worker, support staff). After the introductions, greetings, and morning refreshments, Wanda presented a new behavior plan, emphasizing positive behavior intervention supports (PBIS) over punitive and reactive approaches. She emphasized the necessity of a cooperative team effort, rather than a top-down directive with punitive threats for noncompliance. Wanda presented the new plan and its benefits for all involved. Yet, she emphasized that the new schoolwide PBIS plan was mandatory and clarified expectations for each role. While touting the necessity of staff cooperation, Wanda also assured them that the administrative team would provide consistent support to staff and students.

Wanda had an open-door policy and encouraged staff to meet with her for any feedback or concerns regarding the schoolwide behavior plan. She considered all staff concerns around implementing and enforcing the new PBIS initiative, but ultimately, she made decisions that 
could not please all. Most of the staff appreciated her willingness to meet with them, individually or in groups, and followed through with Wanda's expectations.

Coinciding with the new PBIS initiative were improvements at Freedom High School. First, the number of student office referrals decreased by nearly $70 \%$. In addition, teachers reported higher job satisfaction and used less sick leave. The next school year, more than $90 \%$ of the faculty returned, which reflected a drastic reduction in turnover. Also noteworthy is that attendance at parent/guardian events increased by more than $400 \%$. Probably the most publicized difference, however, was Freedom High School's dramatic jump in school climate ratings, as assessed by the state's education department.

\section{Systematic Induction}

This example demonstrates how school personnel supported their new leader. Similarly, it is imperative to support new faculty and staff members. Even with rigorous preservice training and supervision, the transition from educator preparation programs to career beginnings can be overwhelming. Research suggests that systematic induction programs, structured processes that support novice educators as they adjust to their new roles, may help boost job performance, reduce burnout, and increase staff retention (Billingsley, 2010; Robinson et al., 2019; Vittek, 2015). Although induction is typically viewed as the responsibility of school leadership, the SPLC model suggests personnel can support this process. For example, induction of a new staff member begins with an administrator pairing the novice educator with a veteran in a similar role (e.g., special education teacher [SET], math teacher, counseling department). Likewise, veteran educators support induction with a willingness to mentor and regularly meet with mentees and coach them throughout the first year (Billingsley, 2010; Borman \& Dowling, 2008). Administrators also should meet regularly with the assigned pairs to assess the progress and impact of the mentorship. Through such monitoring, the administrator supports both the veteran and novice and may provide additional support or connect them with resources specific to their roles (e.g., professional learning communities, opportunities to observe others in similar role). Outside of mentoring, veteran educators support induction by modeling ideal professional behaviors (e.g., high-quality products, respect for other school personnel, commitment to all students). They also provide verbal encouragement, instructional exemplars, and in cases of shared students, support in classroom management. The following example illustrates how systematic mentoring and induction can be implemented:

With great ambition and thoughts of saving the world, Jake was enthusiastic about starting his new career as a SET at Liberty Middle School. Alan, the assistant principal of curriculum and instruction, was responsible for assigning Jake a mentor. He typically pairs Don, a charismatic veteran special educator, with novice SETs. However, he had already been assigned to Edwin, who was hired a few weeks before Jake. Alan knew it would be unfair to overload Don. Fortunately, another veteran SET qualified as a mentor. Elena, however, was reluctant to accept the task, as she was busy with a heavier-than-typical caseload.

Alan initiated a meeting between Elena and Jake. The interactions were awkward, as Elena let Jake know of her limited availability, which happened to be the two afternoons Jake was helping coach the football team. Elena seemed too busy to mentor Jake, and Jake insisted he did not need a mentor. Alan, sensing this tension, then met with the two of them separately. He first thanked them for their commitment to the 1-year mentorship and emphasized the importance of systematic induction. Not only did Alan allude to personal experiences and observations, but he explained the research behind it (e.g., Billingsley, 2010; Vittek, 2015). Alan also heard Elena's and Jake's separate concerns, most of which had to do with time and sensing that each other was not receptive to the pairing. 
Alan, knowing there was no other choice, assured Elena and Jake there would be support for their time, but that he needed their cooperation. Alan granted Elena and Jake excused absences from some of the routine faculty meetings so they could use that time to meet. At the next meeting, Alan helped them develop a schedule that was minimally invasive to preexisting commitments. He also instructed them on topics they needed to cover during the course of the mentorship. After this, Elena and Jake met on their own, with Alan attending periodically.

By the end of the school year, the mentorship benefitted both Jake, the novice teacher, and Elena, the seasoned veteran. Jake developed Individualized Education Programs and behavior plans with Elena's guidance. He also had more opportunities to practice behavior and learning strategies that he learned as a student but never had the chance to apply as a student-teacher. Elena, in return, received her own benefits. She had an epiphany and realized she reached a point in her career that she was simply "going through the motions." Serving as a mentor, however, prompted her to sharpen her skills as a SET. Elena began reading scholarly special education journals and learning about the most recent developments in the field. Such an experience could not happen, however, without administrative support for the mentorship and, ultimately, cooperation from both teachers.

\section{Shared Planning and Workload}

The SPLC model can apply to opportunities to work together and the distribution of that work. All personnel can benefit through teamwork, as it allows them to balance individual strengths and weaknesses, manage a realistic workload, and communicate more effectively with colleagues (Bettini et al., 2016; Egodawatte, McDougall, \& Stoilescu, 2011; Lieberman \& Miller, 2011; Robinson et al., 2019). Despite the benefits of collaboration and shared talents, many school personnel continue to work in isolation of one another (Crabtree, 2014). Shared planning time is not often included in the regular work schedule and many teachers do not have much opportunity to collaborate with their coteachers, grade-level teams, or departmental colleagues (Bettini et al., 2016; Simon \& Johnson, 2015). In fact, many report spending countless hours working in isolation from home, because they would not otherwise complete their work within expected deadlines (Richards, 2012). Thus, the problem is twofold in that teachers not only have a scarcity of planning time, whether collaborative or individual, but they often report heavy workloads that require much extra work outside their contracted work day (Richards, 2012). Similar issues may apply to other school personnel as well, such as counselors, social workers, nurses, or other professionals who could perhaps have greater impact working as a team rather than in isolation (Weist et al., 2012).

Teamwork not only involves shared planning, but it also involves fair workloads for each faculty and staff member. The SPLC model may be applied to circumstances in which administrators afford shared planning and balanced workloads, while personnel effectively use the time they are given. To the extent possible, school principals arguably should be conscientious in scheduling and assigning duties. Teachers and other school personnel support their leaders and colleagues by producing highquality work that reflects such consideration from their leaders. The following example describes how a school principal assigns a fair workload and is likewise supported by his teaching staff:

John, the principal at Independence High School, considered teacher concerns about workload and planning time. For starters, in a seven-period school day, first-year teachers are assigned to teach five courses. First-year teachers also do not serve on committees or as club sponsors. All other teachers are assigned to six courses. To address inclusion, John seeks content-area teachers to voluntarily coteach with special educators. He also considers the strengths of each special educator, knowing that although their certification allows them to coteach any course, they perform best when teaching in stronger content areas. Special- 
educator-general-educator dyads are assigned to teach inclusion courses and allotted an additional planning period. John also works with school guidance counselors to try and assign no more than two different courses to each teacher, to reduce the amount of preparation. In cases where this is not possible, experienced teachers who volunteer to teach more than two courses are excused from some of the additional standard duties (e.g., monitoring the cafeteria, morning bus line, committee participation).

With John's efforts to apply effective leadership practices, it is likewise important that Independence High School teachers maximize these opportunities. In one example, Tammy (a math teacher) and Derek (a special educator) were paired as coteachers. Tammy expressed interest in collaborating with a learning specialist, whereas Derek, who has personal strengths in numerical and analytical skills, requested to work in a math classroom. From the beginning of the year, Tammy and Derek have devoted their additional planning period specifically to the courses they coteach. Because of committing this time to planning and strategizing, their instructional delivery has been effective. Though planning together initially seemed to add work, Tammy and Derek have developed into an efficient team and find themselves taking home less work. Jerry's situation is quite different but has its own benefits. He is a veteran social studies teacher. Once first-year teachers and coteacher dyads were afforded additional planning and others were assigned two course preparations, Jerry was left to handle four different courses over six class periods. Given his course load, he appreciated excusal from other faculty expectations (e.g., committee work, cafeteria monitoring). Jerry was able to use time that would otherwise go to additional duties on his instructional planning. By the end of the year, Jerry stated that by taking advantage of the released responsibilities, he managed to balance the additional course preparations effectively.

\section{Material and Social Resources}

The SPLC model can also help school staff and administrators make the most of their resources. When administrators provide staff with adequate resources (Simon \& Johnson, 2015; Stewart-Banks et al., 2015), they feel empowered to execute their expected tasks (e.g., quality instruction, recordkeeping). Material resources (e.g., teaching tools, technology) facilitate high-quality instruction and classroom management practices. Social resources refer to intangible encouragement, communications, or interactions intended to boost personnel performance. While material and social resources empower staff to perform effectively (Bettini et al., 2016; Bettini et al., 2017), teachers and other personnel must use them as intended and incorporate these resources into their practices. For example, when provided a specific instructional tool, teachers should incorporate it in their instructional practices. When given performance feedback, whether from administrators or senior colleagues, they should use it to sharpen their performance. In the following example, a school principal ensures access to material resources, acquisition of additional funds, and interpersonal communication that encourages a team-based environment:

Michelle is the principal of Victory Elementary School. She advocates for adequate supplies and technology for her school. For programs implemented by her faculty and staff, Michelle ensures they are provided thorough training. To make this work, faculty and staff must implement programs with fidelity. For example, Michelle provided the fifth-grade teams with a tracking program to issue merits and demerits to students based on their behaviors. This facilitates a points-based system students may use to exchange for incentives. For this system to work, all classrooms must consistently apply it. At the beginning of the year, both fifth-grade teams were provided training, but only one consistently used the program. The team that used the program experienced fewer student behavior disruptions and issued fewer referrals for administrative intervention. In contrast, the team that did not use the 
program experienced more disciplinary issues without this system of reinforcements. Thus, the program and expectations were provided by school leadership, but the benefits of implementation required consistent effort from the teaching teams.

Michelle and her assistant principals routinely visit classrooms. Students continue as usual when an administrator makes unannounced visits, because they are accustomed to seeing them. Each administrator also provides feedback, off the record, to give teachers a chance to develop ahead of formal evaluations. For example, through administrative visits and informal dialogue, Vanessa learned she could improve the way she facilitates cooperative groups and peer-assisted instruction. She took this feedback seriously, adjusted her facilitation style, and sought additional feedback from Michelle and her assistant principals. Ultimately, Vanessa's formal evaluations reflected the proficiency she developed through the iterative process with the leadership team.

\section{Conclusion}

Research overwhelmingly associates the role of school leadership in personnel working conditions and professional outcomes (Ansley et al., 2019; Bettini et al., 2016; Billingsley, 2010; Robinson et al., 2019; Simon \& Johnson, 2015; Stewart-Banks et al., 2015). However, little attention has been given to the role of faculty and staff in support of school leadership. While administrators set the tone for workplace dynamics and culture, faculty and staff make decisions, act, and interact in ways that affect their leaders, colleagues, students, and their surroundings. To effectively apply the SPLC model, school administrators and personnel must value each other's contributions, actively participate in school operations, and support each other in the process.

\section{References}

Ansley, B., Houchins, D., \& Varjas, K. (2019). Cultivating positive work contexts that promote teacher job satisfaction and retention in high-need schools. Journal of Special Education Leadership, 32, 3-16.

Bauer, T., \& Ergoden, B. (2015). The Oxford handbook of leader-member exchange. New York, NY: Oxford University Press.

Bettini, E. A., Cheyney, K., Wang, J. \& Leko, C. (2015) Job design: an administrator's guide to supporting and retaining special educators. Intervention in School and Clinic, 50, 221-225. doi:10.1177/1053451214532346

Bettini, E. A., Crockett, J. B., Brownell, M. T., \& Merrill, K. L. (2016). Relationships between working conditions and special educators' instruction. The Journal of Special Education, 50, 178-190. doi:10.1177/0022466916644425

Bettini, E. A., Jones, N. D., Brownell, M. T., Conroy, M. A., Leite, W. L., Crockett, J., \& Benedict, A. (2017). Workload manageability among novice special and general educators: relationships with emotional exhaustion and career intentions. Remedial and Special Education, 38, 246256. doi:10.1177/0741932517708327

Billingsley, B. (2010). Work contexts matter: Practical considerations for improving new special educators' experiences in schools. Journal of Special Education Leadership, 23, 41-49.

Borman, G. D., \& Dowling, N. M. (2008). Teacher attrition and retention: A meta-analytic and narrative review of the research. Review of Educational Research, 78, 367-409.

doi:10.3102/0034654308321455 
Crabtree, P. (2014). Teachers can't thrive when they're working in isolation. Education Week Teacher. Retrieved from http://blogs.edweek.org/teachers/teaching_ahead/2014/11/peerobservation-teachers-improve-collaboration.html

Dulebohn, J. H., Bommer, W. H., Liden, R. C., Brouer, R. L., \& Ferris, G. R. (2012). A meta-analysis of antecedents and consequences of leader-member exchange: Integrating the past with an eye toward the future. Journal of Management, 38, 1715-1759. doi:10.1177/0149206311415280

Egodawatte, G., McDougall, D., \& Stoilescu, D. (2011). The effects of teacher collaboration in Grade 9 applied mathematics. Educational Research for Policy and Practice, 10, 189-209. doi:10.1007/s10671-011-9104-y

Graen, G. B., \& Uhl-Bien, M. (1995). The relationship-based approach to leadership: Development of LMX theory of leadership over 25 years: Applying a multi-level, multi-domain perspective. Leadership Quarterly, 6, 219-247. doi:10.1016/1048-9843(95)90036-5

Ilies, R., Nahrgang, J. D., \& Morgeson, F. P. (2007). Leader-member exchange and citizenship behaviors: A meta-analysis. Journal of Applied Psychology, 92, 269-277.

Kraft, M. A., Papay, J. P., Johnson, S. M., Charner-Laird, M., Ng, M., \& Reinhorn, S. (2015). Educating amid uncertainty: The organizational supports teachers need to serve students in high-poverty, urban schools. Educational Administration Quarterly, 51, 753-790. doi:10.1177/0013161X15607617

Lieberman, A., \& Miller, L. (2011), Learning communities: the starting point for professional learning is in schools and classrooms. Journal of Staff Development, 32, 16-20. Retrieved from http://www.rockyview.ab.ca/home/professional-learning/rvs-plModel/assets/standards/LearningCommunities.pdf

Richards, J. (2012). Teacher stress and coping strategies: A national snapshot. The Educational Forum, 76, 299-316. doi:10.1080/00131725.2012.682837

Robinson, O. P., Bridges, S. A., Rollins, L. H., \& Schumacker, R. E. (2019). A study of the relation between special education burnout and job satisfaction. Journal of Research in Special Educational Needs, 19, 1-9. doi:10.1111/1471-3802.12448

Simon, N., \& Johnson, S. M. (2015). Teacher turnover in high-poverty schools: What we know and can do. Teachers College Record, 117, 1-36. Retrieved from http://isites.harvard.edu/fs/docs/icb.topic1231814.files/Teacher\%20Turnover\%20in\%20HighPoverty\%20Schools.pdf

Stewart-Banks, B., Kuofie, M., Hakim, A., \& Branch, R. (2015). Education leadership styles impact on work performance and morale of staff. Journal of Marketing \& Management, 6, 87-105.

Vittek, J. E. (2015). Promoting special educator teacher retention: A critical review of the literature. SAGE Open, 5, 1-6. doi:10.1177/2158244015589994

Weist, M. D., Mellin, E. A., Chambers, K. L., Lever, N. A., Haber, D., \& Blaber, C. (2012). Challenges to collaboration in school mental health and strategies for overcoming them. Journal of School Health, 82, 97-105. Doi:10.1111/j.1746-1561.2011.00672.x

[Appendix follows] 


\section{Appendix}

\section{Examples of Applications of the School Personnel and Leadership Collaboration (SPLC) Model}

\section{SPLC Mode \\ Component}

Enforcement of

school procedures

Systematic induction and mentoring

\section{Administrator Role}

Train teachers in the school's behavior management and protocols at the

beginning of each school year

Aside from behaviors that place others at risk, empower faculty and staff to handle behavior problems without administrative intervention

Manage expectations of personnel with transparency, consistency, and fairness; handle any extenuating circumstances confidentially and minimally

Serve as a collaborative consultant or designate one for to personnel who seek guidance on student behavior management

Partner veteran mentor teachers with first-year teachers

\section{Personnel Role}

Create classroom expectations with schoolwide system in mind; follow protocol consistently throughout the school year

Follow protocol that range from inclass interventions (e.g., verbal redirection, token economy for positive behavior) to parental involvement before referring student for administrative intervention

Expect to adhere to all personnel responsibilities. Exceptions should be rare and unavoidable; steer clear of personnel affairs irrelevant to oneself; avoid participating in gossip or speculation involving colleagues

In the event of student behavior concerns, seek guidance from the designated collaborative consultant; use feedback to improve practice

Novice teachers should be open to guidance from more experienced peers; veteran teachers must be willing to share knowledge and expertise

\section{Desired Outcome}

Administration and teachers know expectations and protocol from the beginning; less confusion and more clarity; improved student behaviors

Personnel will experience greater empowerment and efficacy in student behavior management; administrators spend less time on student discipline; improved student behaviors

Positive school climate and work context; avoids morale problems related to inconsistencies; collegial relationships improve

Positive behavior supports applied; improved student behaviors

Mentors guide new teachers with their experience in the field; veteran teachers continue professional development in areas of interest to better assist in their roles as mentors; optimized job performance 


\section{SPLC Model \\ Component}

Extended planning for mentors and
mentees

\section{Administrator Role}

\section{Personnel Role}

Effective use of additional time by both veteran and novice teachers

Afterschool mentor-mentee meetings with excused absences from other staff meetings

Excuse mentor-mentee pairs from extra duties in the school.

Shared planning and workload

Allow for common/shared planning for grade level, subject area, or other shared goal teams in school

Respect the teacher's shared planning time; avoid pulling teachers for other tasks or scheduling other required activities during this time

Incorporate professional learning communities; encourage a shared workload by creating a school norm of shared planning

Work-related resources and constructive feedback
Provide necessary work-related resources to the faculty and staff
Effective use of additional time by both veteran and novice teachers

Effective use of additional time by both veteran and novice teachers

All involved personnel should use the time specifically to plan as a team

All involved faculty should use the time specifically to plan as a team

Be willing to contribute strengths and share with others; willing to

learn from others; view school as a place where everyone can succeed rather than compete against one another

Suggest preferred resources to administrators; openness to using provided resources

\section{Desired Outcome}

Extra time allotted for the interactions necessary between the mentor-mentee pair; optimized job performance

Extra time allotted for the interactions necessary between the mentor-mentee pair; optimized job performance

Extra time allotted for the interactions necessary between the mentor-mentee pair; optimized job performance

Personnel will be able to benefit from shared knowledge; may learn new strategies; potentially reduce individual workload by sharing common tasks

The teachers feel that their time is respected by the administration and take it seriously; better prepared for planning time; more likely to use time effectively

Novice educators are supported; veteran educators are introduced to new ideas; a collaborative professional learning community; individual workload and stress is reduced

Personnel will have ownership of the provided materials and be more encouraged to use what they have been given 


\begin{tabular}{|c|c|c|c|}
\hline $\begin{array}{l}\text { SPLC Model } \\
\text { Component }\end{array}$ & Administrator Role & Personnel Role & Desired Outcome \\
\hline & $\begin{array}{l}\text { Train personnel in work-related } \\
\text { resources }\end{array}$ & $\begin{array}{l}\text { Attend trainings as scheduled; seek } \\
\text { guidance as necessary }\end{array}$ & $\begin{array}{l}\text { Faculty and staff will be able to } \\
\text { effectively use their provided materials } \\
\text { to the best of their ability; will gain } \\
\text { confidence in using resource }\end{array}$ \\
\hline & $\begin{array}{l}\text { Give faculty and staff a set amount of } \\
\text { money, provided by the school, to } \\
\text { spend on new materials each year }\end{array}$ & $\begin{array}{l}\text { Spend allotment wisely and use } \\
\text { purchased resources }\end{array}$ & $\begin{array}{l}\text { Personnel will have discretion and } \\
\text { autonomy in instruction and other } \\
\text { classroom procedures }\end{array}$ \\
\hline & $\begin{array}{l}\text { Regularly visit individual learning } \\
\text { environments for informal } \\
\text { observations }\end{array}$ & $\begin{array}{l}\text { Reflect on informal feedback; ask for } \\
\text { guidance as necessary; use feedback } \\
\text { to improve practice }\end{array}$ & $\begin{array}{l}\text { Formal observations will be less } \\
\text { stressful; opportunities for reflection; } \\
\text { allows faculty and staff space to } \\
\text { explain their practice style and } \\
\text { decision making to the administration } \\
\text { before a formal observation; formal } \\
\text { observation more reflective of typical } \\
\text { day, as visits from administrators will } \\
\text { be the norm; allows more interaction } \\
\text { between administrators and students }\end{array}$ \\
\hline & $\begin{array}{l}\text { Feedback is constructive, rather than } \\
\text { punitive; aim for professional growth; } \\
\text { reinforce faculty and staff for positive } \\
\text { aspects of job performance }\end{array}$ & $\begin{array}{l}\text { Use feedback to improve } \\
\text { performance; ask for guidance as } \\
\text { necessary }\end{array}$ & $\begin{array}{l}\text { Personnel will feel supported; self- } \\
\text { efficacy in job performance; open to } \\
\text { continuous growth }\end{array}$ \\
\hline
\end{tabular}


The Journal of Educational Research and Practice provides a forum for studies and dialogue that allows readers to better develop social change in the field of education and learning. Journal content may focus on educational issues of all ages and in all settings. It also presents peer-reviewed commentaries, book reviews, interviews of prominent individuals, and additional content. The objectives: We publish research and related content that examines current relevant educational issues and processes aimed at presenting readers with knowledge and showing how that knowledge can be used to impact social change in educational or learning environments. Additional content provides an opportunity for scholarly and professional dialogue regarding that content's usefulness in expanding the body of scholarly knowledge and increasing readers' effectiveness as educators. The journal also focuses on facilitating the activities of both researcher-practitioners and practitioner-researchers, providing optimal opportunities for interdisciplinary and collaborative thought through blogging and other communications.

Walden University Publishing: http://www.publishing.waldenu.edu 